\title{
ANALISIS PERHITUNGAN DAN PENCATATAN AKUNTANSI PAJAK PENGHASILAN ATAS BUNGA DEPOSITO DAN TABUNGAN NASABAH PADA PT. BANK SYARIAH MANDIRI CABANG MANADO
}

\author{
Nurgita Tingginehe ${ }^{1}$, Jullie J. Sondakh ${ }^{2}$, Winston Pontoh $^{3}$ \\ 1,2,3 Jurusan Akuntansi Fakultas Ekonomi dan Bisnis, Universitas Sam Ratulangi, Jl. Kampus Bahu, Manado, \\ 95115, Indonesia \\ E-mail : tingginehebrigitta@gmail.com
}

\begin{abstract}
The contribution to the state and the source of our income comes from taxes. One of the final income tax objects is the interest rate on deposits and customer saving. This study aims to find out how to calculation and record of accounting deposit interest rate and savings customers at PT. Bank Syariah Mandiri Branch Manado. The analytical method used is descriptive analysis of research data obtained from interviews and literature studies. The results of the study show the count of income tax on interest deposits customers from PT. Bank Syariah Mandiri Branch Manado has been accordance with goverment regulations No.131 of 2000 and KMK-51/KMK.04/2001. And accounting records has been accordance with accounting PSAK 101 Syariah. PT. Bank Syariah Mandiri Branch Manado must improve service quality for improvement costumers.

Keywords:Calculation, Recording, Deposit Interest, Customer Savings
\end{abstract}

\section{PENDAHULUAN}

Untuk membangun negeri agar makmur dan sejahtera maka diperlukan pembangunan untuk memakmurkan rakyat. Pembangunan tidak akan berjalan dengan baik ketika tidak ada kerjasama antar pemerintah dan masyarakat. Agar supaya pembangunan bisa terlaksana seperti kehendak rakyat Indonesia. Di sisi lain hal yang berperan sangat penting untuk membangun adalah dana dan dana yang paling banyak bersumber dari pajak yang dipungut. Dan pada dasarnya, pajak ialah iuran untuk Negara yang terutang oleh WP yang dapat dibayar sesuai aturan dan tidak mendapatkan prestasi ulang yang dan dipilih untuk membayar pengeluaran publik yang sehubungan atas tugas bangsa, dan sumber penerimaan negara kita berasal dari pajak. Oleh sebab itu dapat dilihat bahwa pajak memiliki kontribusi yang patut untuk negeri terhutang dari OP dan badan yang bersifat "memaksa" mendasari perundang-undangan, dengan tidak mendapatkan imbalan secara langsung dan digunakan untuk kepentingan bangsa bagi sebesar-besarnya kemakmuran rakyat (Mardiasmo 2018 : 3).

Pemerintah menerapkan aturan baru dengan mengganti aturan lama mengenai system pemungut pajak dari official assessment system menjadi self assessment system. Dalam self assessment system, wajib pajak diberikan wewenang untuk secara pribadi menghitung besar pajak terhutang dan memberitahukan sesuai dengan pajak yang terhutang dan yang sudah dilunaskan seperti dalam aturan undang-undang pajak yang berlaku. Wajib pajak diberikan kebebasan dalam menghitung pajaknya selama tidak menyalahi aturan yang tertulis. PPh final pasal 4 ayat (2) ialah pajak di potong serta di pungut bersifat final, yang ditentukan atas beberapa jenis penghasilan tertentu sebagaimana sudah diatur dalam UU No. 36 tahun 2008 pasal 4 ayat 2. Maksud observasi ini yaitu untuk memahami:

1. Penghitungan bunga deposito dan tabungan nasabah pada PT. Bank Syariah Mandiri Cabang Manado

2. Penghitungan dan pencatatan akuntansi PPh Final pasal 4 ayat 2 atas bunga deposito dan tabungan nasabah pada PT. Bank Syariah Mandiri Cabang Manado 


\section{TINJAUAN PUSTAKA}

Konsep Dasar Akuntansi. Akuntansi adalah suatu proses seni untuk mencatat, menggolongankan , meringkas, dan menyajikan secara tertentu atas setiap transaksi laporan keuangan yang terjadi di sebuah perusahaan. Menurut Tangka (2014), konsep dari Akuntansi adalah proses pencatatan, mengklasifikasikan, mengolah dan membuat data, transaksi dan peristiwa yang sehubungan untuk laporan keuangan agar kita dapat mengambil keputusan secara tepat. Menurut Ismail (2014), akuntansi bisa didefinisikan seperti seni untuk melakukan pencatatan, penggolongan, dan pengikhtisaran, agar laporan akhir sesuai dengan informasi laporan keuangan. Menurut Herduard (2015), Akuntansi adalah proses, dapat di artikan sebagai data mentah dan kemudian di olah menjadi sebuah data yang siap untuk dipakai, dan didalamnya ada berbagai kegiatan berupa pengumpulan, pengidentifikasian, pencatatan, dan pengiktisaran dari data laporan keuangan.

Akuntansi Pajak. Akuntansi pajak dalah akuntansi yang diterapkan dengan tujuan untuk menetapkan besarnya pajak terutang. Akuntansi adalah suatu proses pencatatan, penggolongan, pengikhtisaran transaksi-transaksi keuangan menjadi sebuah laporan keuangan. Pajak ialah iuran serta pungutan wajib rakyat untuk negara berkarakter, karena diatur dalam perundang-undangan, serta tidak adanya imbalan bersifat resmi serta dipakai guna pembiayaan umum, jadi pajak berasal dari rakyat, oleh rakyat, dan digunakan untuk kepentingan bersama masyarakat suatu negara. Menurut Waluyo (2012) mengartikan untuk menerapkan jumlah pajak terutang harus mendasari laporan keuangan yang dibuat dari perusahaan, agar sesuai undang-undang yang berlaku serta aturan yang relevansi untuk akuntansi. Menurut Rahman (2013) menyatahkan di dalam perpajakan, akuntansi sering disebut menggunakan sebutan pembukuan dan penulisan laporan keuangan.

Konsep Perpajakan. Membayar pajak berarti menyerahkan sebagian kekayaan milik pribadi kepada Negara untuk dikelola demi keperluan bersama. Pajak diatur dalam UndangUndang sehingga dalam pelaksanannya dapat dipaksakan. "Dipaksakan" dalam hal ini adalah teks peringatan, dan diberikan denda untuk penyitaan kekayaan, serta dengan pidana bagi wajib pajak yang tidak memenuhi kewajiban perpajakan dan dapat diartikan bahwa uang yang telah terkumpul dari pungutan pajak harus dikembalikan kepada rakyat untuk dapat membangun dan pelayanan yang diberikan dari pemerintahan. Menurut Harmanto (2013) menu pajak ialah untuk membayar atau membebankan tidak secara langsung sesuatu yang sehubungan dengan barang atau jasa yang dalam wilayah atau jangkauan pemerintah.

Simpanan Berjangka Atau Deposito. Menurut (Kabir, et,al.2014) Deposito ialah jumlah nominal yang dapat kita setor dari seorang debitur atau penyewa seperti memanjar uang atau dapat dibayar dimuka, dan jumlah itu dibayar pada kreditur, dan akan dibayar dengan melunasi uang atau bisa juga ditransfer dari penyerahan barang.

Pajak Penghasilan. Membayar pajak sudah menjadi kewajiban bagi setiap warga negara yang memperoleh penghasilannya dari Indonesia, definisi penghasilan menurut Undang-undang PPh: Penghasilan ialah tambahan ekonomis yang didapat wajib pajak, dan bersumber dari Indonesia serta luar negeri, dan dibuat supaya konsumsi dan membuat harta wajib pajak bersangkutan, juga nama serta objek pajak. Pajak penghasilan adalah pajak yang diambil dari objek pajak serta penghasilan. (Watung, 2016). Nelwan (2013) mendefinisikan penghasilan seperti meningkatkan ekonomi selama satu periode akuntansi dalam pemasukan atau ditambah dengan aktiva serta mengakibatkan penurunan kewajiban.

PP No. 46 Tahun 2013. Peraturan Pemerintah nomor 46 tahun 2013 adalah aturan perpajakan tentang Pajak Penghasilan yang bersifat final yang dipungut oleh pendapatan oleh usaha uang didapat serta oleh WP yang mempunyai peredaran bruto. Pihak yang dikenakan aturan ini ialah WP orang Pribadi serta Wajib Pajak Badan yang memiliki pendapatan dari usaha, dan tidak tercatat penghasilan oleh jasa berhubung pekerjaan bebas. Besarnya tarif $\mathrm{PPh}$ final tersebut adalah 1\%. Apabila peredaran bruto WP telah melampaui jumlah Rp4,8 
miliar untuk satu tahun pajak, atas pendapatan yang diterima wajib pajak pada tahun pajak selanjutnya akan dikenakan tarif pajak penghasilan sesuai dengan ketentuan perundangundangan $\mathrm{PPh}$.

PPh Final Pasal 4 ayat (2). Pajak penghasilan final pasal 4 ayat 2 merupakan pajak atas penghasilan berupa deposito dan tabungan serta diskonto sertifikat Bank Indonesia (SBI) dipotong PPh final. Serta pajak atas penghasilan seperti bunga deposito serta tabungan lain, bunga obligasi dan surat utang negara, serta bunga simpanan penghasilan berupa hadiah undian, penghasilan dari transaksi saham dan sekuritas lainnya. Menurut Kotambunan dan Sondakh (2016) Pajak final atas bunga deposito dan tabungan nasabah menjadi tugas utama yang harus dipungut, dipotong, dan dilaporkan perusahaan pemberi deposito dan tabungan. Perhitungan yang dilakukan oleh perusahaan bukan hanya sekedar terfokus pada perhitungan pemberian bunga atas deposito dan tabungan yang menjadi kewajiban sebuah perusahaan kepada nasabah untuk pengurangan $\mathrm{PPh} 4$ (2) untuk bunga deposito serta tabungan nasabah harus menjadi fokus selanjutnya yang harus diselesaikan oleh pihak perusahaan.

Dasar Hukum PPh Pasal 4 (2). Adapun dasar hukum yang digunakan adalah: (1) PP No. 131 Tahun 2000; (2) KMK-51/KMK.04/2001; dan (3) SE-29/PJ.43/2001.

\section{Jatuh Tempo PPh Final Pasal 4 Ayat (2)}

a. Pajak Penghasilan pasal 4 ayat 2 dipotong dari potongan PPh dan dibayar paling lambat tanggal 10 bulan berikut sesudah masa pajak selesai, atau diatur Menteri Keuangan.

b. Pajak Penghasilan pasal 4 (2) harus disetor sendiri oleh WP dan dibayar paling lambat tanggal 15 sesudah bulan berikut sesudah masa pajak selesai kecuali ditetapkan Menteri Keuangan.

c. WP orang pribadi serta badan, baik akan membuat pembayaran pajak sendiri ataupun ditetapkan seperti dipotong serta dipungut Pajak Penghasilan harus memberitahukan Surat Pemberitahuan (SPT) Masa PPh 4 (2) setidaknya kurang 20 hari sesudah Masa Pajak selesai.

Tarif PPh Final Pasal 4 ayat (2) Atas Bunga Deposito dan Tabungan. Penghasilan dipotong PPh final pasal 4 (2) yaitu pengasilan atas bunga deposito dan tabungan dengan jumlah deposito dan tabungan lebih dari Rp.7.500.000 dan tidak merupai besaran yang dipisah. Apabila tidak melebihi jumlah yang ditentukan tersebut maka tidak akan dipotong pajak. PPh yang dipotong $20 \%$ dari jumlah bruto.

\section{$P P h($ final $)=20 \% \times$ bunga deposito}

Penghasilan yang didapat dari bunga deposito dan tabungan yang telah diatur diluar negara lewat bank yang dibangun di Indonesia serta cabang yang berada di bank luar negeri di Indonesia dan harus dipotong pajak sebanyak $20 \%$. Untuk itu wajib pajak luar negeri selain Bentuk Usaha Tetap, dipotong pajak sebesar $20 \%$ atau sesuai ketentuan dalam Perjanjian Penghindaran Berganda (P3B).

Penelitian Terdahulu. Mokoagow (2016) dalam penelitian yang berjudul Analisis perhitungan PPh Final pasal 4 (2) atas bunga deposito dan tabungan nasabah pada PT. Bank Sulut Cabang Kotamobagu. Hasil penelitian tersebut memperlihatkan penghitungan PPh 4 (2) untuk bunga deposito serta tabungan nasabah PT. Bank Sulut cabang Kotamobagu sudah mengikuti kebijakan undang-undang yang diberlakukan. Muhea (2016) dalam penelitian yang berjudul Analisis Penyetoran, Pelaporan, dan Pencatatan PPh 4 (2) untuk Bunga Deposito serta Tabungan Nasabah pada BPR Prisma Dana Cabang Amurang. Hasil penelitian menunjukkan bahwa telah sesuai dengan PP No. 131 tahun 2000 BPR Prisma Dana Cabang Amurang membuat potongan Pajak Penghasilan Final Pasal 4 (2) untuk bunga deposito dan tabungan nasabah dimana jumlah deposito dan tabungan yang nominal melewati Rp7.500.000 akan dikenai pajak sesuai tarif sebesar 20\% dari jumlah bruto. 


\section{METODE PENELITIAN}

Jenis Penelitian. Penelitian yang digunakan adalah penelitian metode deskriptif. Penelitian yang dilakukan untuk mengetahui nilai masing-masing variabel. Variabel tersebut dapat menggambarkan secara sistematik dan akurat mengenai populasi atau mengenai bidang tertentu menurut V. Wiratna (2014).

Tempat dan Waktu Penelitian. Penelitian ini dilakukan di PT. Bank Syariah Mandiri Cabang Manado dan berlokasi di Jln. Piere Tendean Boulevard Blok I D1 No. 28 Manado. Waktu pengambilan data dimulai pada bulan Maret dan April 2018.

Prosedur Penelitian. Prosedur yang dibuat peneliti dalam proses penelitian adalah dengan tahap-tahap seperti ini: (1) merumuskan masalah serta menetapkan prosedur penelitian; (2) pengajuan permohonan penelitian; (3) pengumpulan data; (4) menganalisis data; dan (5) menarik kesimpulan.

\section{Metode Pengumpulan Data}

Jenis Data. Jenis data yang digolongkan menjadi dua, yaitu:

1. Data Kuantitatif: adalah data yang berupa bilangan atau angka. Dapat dianalisis dengan Teknik perhitungan statistik.

2. Data Kualitatif: adalah data yang dinyatakan bukan dalam bentuk angka melainkan dapat berupa kata, skema, atau gambar. Biasanya, menjelaskan karakteristik atau sifat.

Sumber Data. Dalam penelitian ini menggunakan dua sumber data, yakni data primer dan data sekunder.

1. Data primer: didapat ketika peneliti melakukan penelitian langsung di lapangan.

2. Data sekunder: berasal dari informasi yang telah diolah dalam bentuk tulisan literature buku, dokumen, catatan atau yang berasal dari pihak lain.

Teknik Pengumpulan Data. Teknik pengambilan data yang dipakai untuk penelitian adalah Teknik observasi, wawancara, dan dokumentasi.

1. Teknik observasi: melakukan observasi atau melihat langsung dengan mengunjungi PT. Bank Syariah Mandiri Cabang Manado yang berlokasi di Jln. Piere Tendean Boulevard Blok I D1 No. 28 Manado.

2. Teknik Wawancara: melakukan wawancara dengan Kasie Umum, SDM, dan Akuntansi Bank Syariah Mandiri Cabang Manado.

3. Teknik Dokumentasi: mempelajari literature buku yang memberikan informasi berkaitan dengan penelitian, serta dokumen dan catatan-catatan yang diberikan pihak Bank Syariah Mandiri Cabang Manado

Metode Analisis Data. Metode analisis data yang dipakai ialah metode deskriptif. Teknik yang akan dibuat yaitu:

1. Mengumpul data dan informasi yang dibutuhkan.

2. Mengetahui peraturan yang berlaku terkait pajak atas bunga deposito dan tabungan nasabah.

3. Menguraikan penghitungan serta potongan atas bunga deposito serta tabungan nasabah.

4. Menganalisa tahapan penghitungan serta pencatatan akuntansi PPh Final Pasal 4 ayat 2 apakah sudah mengikuti peraturan perpajakan yang telah diterapkan.

5. Menarik kesimpulan dari penelitian yang telah dilakukan. 


\section{HASIL PENELITIAN DAN PEMBAHASAN}

\subsection{Hasil Penelitian}

Tabel 1. Suku Bunga Tabungan PT. Bank Syariah Mandiri Cabang Manado

\begin{tabular}{lc}
\hline \multicolumn{1}{c}{ Nominal Tabungan } & Nisbah \\
\hline s.d Rp.10.000.000 & $15 \%$ \\
Rp.10.000.000 s.d Rp.100.000.000 & $15 \%$ \\
Rp.100.000.000 s.d Rp.500.000.000 & $15 \%$ \\
Rp.500.000.000 s.d Rp.1.000.000.000 & $15 \%$ \\
>Rp.1.000.000.000 & $15 \%$ \\
\hline
\end{tabular}

Sumber: PT. Bank Syariah Mandiri Cabang Manado

Ket: Nisbah = Suku Bunga

Tabel 2. Suku Bunga Deposito PT. Bank Syariah Mandiri Cabang Manado

\begin{tabular}{cc}
\hline Jangka Waktu & Nisbah \\
\hline 1 Bln & $46 \%$ \\
3 Bln & $47 \%$ \\
6 Bln & $48 \%$ \\
12 Bln & $49 \%$ \\
\hline
\end{tabular}

Sumber: PT. Bank Syariah Mandiri Cabang Manado

Penghitungan Bunga Deposito Nasabah serta Pemotongan Pajak Penghasilan Pasal 4 ayat 2 atas Bunga Deposito PT. Bank Syariah Mandiri Cabang Manado

1. Tanggal 10 Juli 2017 Bapak A mendepositkan dana bentuk deposit pada PT. Bank Syariah Mandiri Cabang Manado sebanyak Rp.4.500.000,- dan dalam jangka waktu 30 hari (dan suku bunga yang diberikan ialah $46 \%$ )

Penghitungan Bunga:

Bunga Deposito $=$ JD $x$ SB

$$
\begin{aligned}
& =\text { Rp.4.500.000,- x } 46 \% \\
& =\text { Rp.2.070.000,- }
\end{aligned}
$$

Ket: JD (Jumlah Deposito) x SB (Suku Bunga)

Peraturan Pemerintah No. 131 Tahun 2000, mengenai bunga deposito dan tabungan nasabah juga diskonto Sertifikat Bank Indonesia serta nominal tidak melewati Rp.7.500.000 serta tidak menjadi jumlah yang dipecah serta tidak akan dipotong Pajak Penghasilan Final Pasal 4 (2)

2. Tanggal 11 Mei 2017 Ibu D mendepositkan dana bentuk deposito pada PT. Bank Syariah Mandiri Cabang Manado sebanyak Rp.60.000.000 dan dalam jangka waktu pencairan 6 bulan.

Penghitungan bunga:

Bunga Deposit

$$
\begin{aligned}
& =\mathrm{JD} \times \mathrm{SB} \\
& =\mathrm{Rp} .60 .000 .000 \times 48 \% \\
& =\mathrm{Rp} .28 .800 .000
\end{aligned}
$$

Ket: JD (Jumlah Deposito) x SB (Suku Bunga)

Dikarenakan hasil pendapatan Deposito Ibu D melewati Rp.7.500.000 akan dipotong dengan PPh 4 (2).

Jumlah PPh yang dipotong adalah 20\% dari jumlah bruto. dan penghitungan seperti ini:

PPh Final 4 Ayat 2

$$
\begin{aligned}
& =\text { Penerimaan Bunga Brutto x } 20 \% \\
& =\text { Rp. } 28.800 .000 \times 20 \% \\
& =\text { Rp. } 5.760 .000
\end{aligned}
$$


Jadi, untuk penerimaan Bunga Netto Deposito Ibu D ialah:

Penerimaan Bunga Netto= $\quad=$ Penerimaan Bunga Bruto $-\mathrm{PPh} 4$ (2)

$$
\begin{aligned}
& =\text { Rp.28.800.000 - Rp.5.760.000 } \\
& =\text { Rp.23.040.000 }
\end{aligned}
$$

Akuntansi yang tercatat berlangsung disaat bunga tabungan atau deposito serta akan dipotong pajak dari pihak ketiga atau pihak bank dan akan segera dicatat sebagai berikut.

Beban bunga

Utang bunga

PPh Final Pasal 4 Ayat (2)

Rp.28.800.000,-

Rp. 23.040.000,-

$$
\text { Rp.5.760.000,- }
$$

Potongan PPh final untuk bunga deposito pada PT. Bank Syariah Mandiri Cabang Manado langsung dibuat oleh PT. BSM Cabang Manado secara otomatis oleh sistem komputerisasi sehingga mempermudah dan mengurangi resiko kesalahan penghitungan oleh pegawai.

Penghitungan Bunga dan Pemotongan Pajak PPh Pasal 4 ayat 2 atas Tabungan Nasabah pada PT. Bank Syariah Mandiri Cabang Manado

1. Berikut ialah catatan tabungan Ibu G pada bulan mei 2017

Tabel 3. Transaksi buku rekening Ibu G bulan Mei 2017

\begin{tabular}{cccc}
\hline Tgl & Debet & Kredit & Saldo \\
\hline $07-05-2017$ & & 500.000 \\
$10-05-2017$ & & 2.000 .000 & 2.500 .000 \\
$15-05-2017$ & 600.000 & & 1.900 .000 \\
$22-05-2017$ & & 1.100 .000 & 3.000 .000 \\
$27-05-2017$ & & 1.250 .000 & 4.250 .000 \\
\hline
\end{tabular}

Sumber:data olahan, 2018

Penghitungan bunga memakai metode saldo harian

Bunga yang diperoleh $=($ Rp. $500.000 \times 15 \% \times 3: 365) \quad=R p .616,43$

$($ Rp. $2.500 .000 \times 15 \% \times 12: 365) \quad=$ Rp. 12,328

$($ Rp. $1.900 .000 \times 15 \% \times 7: 365) \quad=$ Rp. $5.465,7$

$($ Rp.3.000.000 x $15 \%$ x $4: 365) \quad=$ Rp. $4.931,5$

(Rp.4.250.000 x $15 \%$ x $5: 365) \quad=$ Rp.8.732,8

$=$ Rp. 265.271

Sesuai dengan Peraturan Pemerintah No. 131 Tahun 2000 yang nominal tidak melewati Rp. 7.500.000 tidak akan dipotong PPh 4 (2).

2. Buku rekening tabungan Bapak P pada bulan November 2017

Tabel 4. Transaksi Tabungan Bapak $P$

\begin{tabular}{cccc}
\hline Tgl & Debet & Kredit & Saldo \\
\hline $02-11-2017$ & & 15.000 .000 & 15.000 .000 \\
$06-11-2017$ & & 10.000 .000 & 25.000 .000 \\
$15-11-2017$ & 8.000 .000 & 32.000 .000 \\
$21-11-2017$ & 6.000 .000 & & 26.000 .000 \\
$26-11-2017$ & & 16.000 .000 & 42.000 .000 \\
\hline
\end{tabular}

Sumber: Data olahan, 2018

Memakai metode saldo harian

$$
\text { BT } \quad \begin{array}{rlrl} 
& =(\operatorname{Rp} .15 .000 .000 \times 15 \% \times 3: 365) & =\mathrm{Rp} .18 .493 \\
& & =(\operatorname{Rp} .25 .000 .000 \times 15 \% \times 12: 365) & =\mathrm{Rp} .123 .287
\end{array}
$$




$$
\begin{aligned}
& =(\text { Rp. 32.000.000x 15\% } 7: \text { :365) }=\text { Rp.92.054 } \\
& =(\text { Rp. } 26.000 .000 \times 15 \% \times 4: 365) \quad=\text { Rp.47.739 } \\
& =(\mathrm{Rp} .42 .000 .000 \times 15 \% \times 5: 365) \quad=\mathrm{Rp} .86 .301 \\
& \text { Rp.367.928 }
\end{aligned}
$$

\section{Ket $=$ BT $($ Bunga Tabungan $)$}

Karena banyaknya saldo tabungan yang diperoleh oleh Bapak $\mathrm{P}$ adalah sebesar Rp.42.000.000 dan saldo tabungan bapak P melewati Rp.7.500.000 jadi harus dipotong PPh 4 (2) dan pajak sebesar $20 \%$.

Penghitungan pajak:

$$
\begin{array}{ll}
\text { PPh } 4 \text { (2) } & =\text { Pendapatan Bunga Bruto } \times 20 \% \\
& =\mathrm{Rp} .367 .928 \times 20 \% \\
& =\mathrm{Rp} .73 .585,- \\
& \\
\text { BB } & =\mathrm{Rp} .367 .928-\mathrm{Rp} .73 .585 \\
& =\mathrm{Rp} .294 .343 \\
\text { Ket = BB (Bunga Bersih) } &
\end{array}
$$

Jadi untuk penerimaan bunga bapak P di bulan November telah dikenakan PPh Pasal 4 ayat 2 sebanyak Rp.73.585,- Untuk potongan PPh final telah dibuat oleh PT. Bank Syariah Mandiri Cabang Manado dan potongan secara otomatis dan sistem komputer untuk rekening tabungan nasabah setiap bulan.

Pencatatan Akuntansi Terhadap Pemotongan dan Penyetoran PPh Pasal 4 ayat 2 Atas Bunga Deposito dan Tabungan Nasabah pada PT. Bank Syariah Mandiri Cabang Manado

Akuntansi yang tercatat terjadi ketika diakui bunga tabungan/deposito dan dipotong pajak dari pihak ketiga/pihak bank.

Beban bunga tabungan Bapak N Rp.367.928

$$
\begin{array}{ll}
\text { Tabungan bapak } \mathrm{N} & \text { Rp.294.343,- } \\
\text { Utang pajak bunga tabungan } & \text { Rp.737.585,- }
\end{array}
$$

Akuntansi yang tercatat terjadi ketika pajak akan disetor/dibayar oleh pihak pemotong pajak,

$$
\begin{aligned}
& \text { Utang pajak bunga tabungan } \quad \text { Rp.737.585,- } \\
& \text { Kas/Bank }
\end{aligned}
$$

Karena hutang pajak yang sudah diakui oleh pihak bank, maka segera disetorkan kepada kas negara setiap berakhirnya bulan. 


\subsection{Pembahasan}

Penerapan Peraturan Pemerintah 131 Tahun 2000 tentang PPh Atas Bunga Deposito dan Tabungan Serta Diskonto SBI Pada PT. Bank Syariah Mandiri Cabang Manado.

Tabel 5. Penerapan Peraturan Pemerintah No. 131 Tahun 2000 pada PT. Bank Syariah Mandiri Cabang Manado

\begin{tabular}{|c|c|c|}
\hline PP. 131 Tahun 2000 & Evaluasi & Keterangan \\
\hline $\begin{array}{l}\text { 1. untuk pendapatan seperti bunga } \\
\text { deposito serta tabungan dan } \\
\text { diskonto SBI dikenakan PPh yang } \\
\text { bersifat final. }\end{array}$ & Telah sesuai & 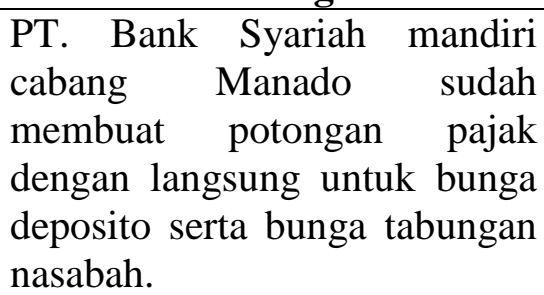 \\
\hline $\begin{array}{l}\text { 2. Dipotong PPh Final } 4 \text { (2) } \\
\text { sebanyak 20\% dari jumlah bruto } \\
\text { sesuai WP dalam negeri maupun } \\
\text { BUT. }\end{array}$ & telah sesuai & $\begin{array}{l}\text { PT. Bank } \begin{array}{r}\text { Syariah Mandiri } \\
\text { Cabang Manado }\end{array} \text { sudah } \\
\text { membuat potongan otomatis } \\
\text { sesuai system komputer untuk } \\
\text { bunga deposito serta tabungan } \\
\text { nasabah sebanyak 20\% untuk } \\
\text { jumlah bruto. }\end{array}$ \\
\hline $\begin{array}{l}\text { 3. Pemotongan PPh Final Pasal } 4 \\
\text { Ayat } 2 \text { tidak akan diberlakukan } \\
\text { terhadap bunga dari deposito serta } \\
\text { tabungan nasabah dan Sertifikat } \\
\text { Bank Indonesia yang tak melewati } \\
\text { Rp.7.500.000 dan tidak menyerupai } \\
\text { besaran yang dipisah. }\end{array}$ & telah sesuai & $\begin{array}{l}\text { PT. Bank Syariah } \\
\text { Cabang Mandiri } \\
\text { memberlakukan } \text { Manado } \\
\text { pajak terhadap bunga deposito } \\
\text { serta tabungan nasabah untuk } \\
\text { jumlah minim } \\
\text { Rp7.500.000 }\end{array}$ \\
\hline
\end{tabular}

Sumber: data olahan, 2018

Tabel 5, menunjukkan bahwa hasil dari penelitian yang telah dikerjakan pada PT. Bank Syariah Mandiri Cabang Manado, atas dasar Peraturan Pemerintah No. 131 Tahun 2000 PT. Bank Syariah Mandiri Cabang Manado tak akan membuat potongan Pajak penghasilan Pasal 4 (2) untuk bunga deposito serta tabungan nasabah dan angkanya tak melewati Rp 7.500.000, serta sudah seperti perundang-undangan No. 36 Tahun 2008, dan juga pungutan pajak yang dipakai ialah 20\% dari bruto yang melewati Rp.7.500.000,-. Dan untuk pencatatan akuntansinya PT. Bank Syariah Mandiri Cabang Manado menggunakan sistem pencatatan akuntansi PSAK - Syariah dan telah sesuai dengan konsep akuntansi yang ada serta tidak terjadi kesalahan dalam hal pencatatan akuntansinya.

\section{KESIMPULAN DAN SARAN}

\subsection{Kesimpulan}

Kesimpulan dari penelitian ini ialah:

1. Perhitungan bunga tabungan dan penghitungan pajak atas bunga deposito pada PT. Bank Syariah Mandiri cabang Manado menggunakan metode saldo harian dan telah seperti perundang-undangan pajak yang ada.

2. Pencatatan akuntansi yang diberlakukan untuk potongan dan penyetoran $\mathrm{PPh}$ Pasal 4 (2) pada PT. Bank Syariah Mandiri Cabang Manado sudah seperti konsep akuntansi yang berlaku. 


\subsection{Saran}

Saran dari penelitian adalah:

1. Agar PT. Bank Syariah Mandiri Cabang Manado selalu mempertahankan kualitas pelayanannya terhadap nasabah untuk lebih baik lagi dalam pelayanan pinjaman atau simpanan.

2. Sebaiknya kualitas pelayanan yang diberikan terhadap peneliti lebih ditingkatkan lagi dalam hal pengambilan data.

3. Untuk peneliti selanjutnya agar dapat lebih memperluas lagi data yang akan diteliti, agar supaya bukan hanya pada penghitungan dan dicatatnya akuntansi Pajak Penghasilan Final 4 ayat (2) untuk bunga deposito dan tabungan nasabah.

\section{DAFTAR PUSTAKA}

Harmanto. 2013. Perencanaan Pajak. Cetakan Pertama. BPFE, Yogyakarta.

Herduard R. Homenta 2015. Perhitungan, Pemotongan, Pencatatan dan Pelaporan

Pajak Penghasilan Pasal 21 Pada CV. Multi Karya Utama. Universitas Sam Ratulangi, Manado. Jurnal Emba

Ismail, Molamahu. 2014. Pengaruh Pengelolaan Keuangan Daerah dan Sistem

Akuntansi Keuangan Daerah Terhadap Kinerja Pemerintah Daerah

Kabupaten Bone, Bolango. Jurnal Skripsi. Fakultas Ekonomi dan Bisnis Universitas Negeri Gorontalo, Gorontalo.

Kabir, Muhammad. 2014. A Company Analysis of Profit Rate on Deposit in $\quad$ Islamic Banks in Bangladesh. Journal International.

Kotambunan, B dan J. J Sondakh. 2016. Analisis PPh Final Pasal 4 Ayat 2 Atas Bunga

Deposito dan Tabungan Nasabah Pada PT BPR Millenia Manado dan PT BPR

Celebes Mitra Perdana Manado. Universitas Sam Ratulangi Manado. Jurnal Emba.

Mardiasmo. 2018. Perpajakan edisi terbaru. Yogyakarta: Andi

Mokoagow, W, Wardani. 2015. Analisis Perhitungan PPh Final Pasal 4 Ayat 2

Atas Bunga Deposito dan Tabungan Nasabah Pada PT. Bank Sulut Cabang

Kotamobagu. Universitas Sam Ratulangi, Manado. Jurnal Emba

Nelwan, Tirsa. 2013. Evaluasi Pemotongan, Penyetoran, dan Pelaporan PPh Pasal

23 Pada BPR Prisma Dana Manado. Jurnal Emba,_ Vol.1 No.3 ISSN 23031174.

Rahman, Arif. 2013. Panduan Akuntansi dan Perpajakan. Transmedia, Jakarta.

Tangka, Ireine, S. 2014. Analisis Perhitungan PPh Final Pasal 4 ayat 2 Atas Bunga

Deposito dan Tabungan Nasabah pada PT. Bank Rakyat Indonesia (Persero), Tbk.

Universitas Sam Ratulangi. Manado. Jurnal Emba, Vol. 2 No.4 ISSN 2303117.

Wiratna, V, Sujarweni. 2014. Metodologi Penelitian. Yogyakarta :

Pustaka Baru Press

Waluyo. 2012. Akuntansi Pajak (Edisi 4). Jakarta: Salemba Empat

Watung, Leonardo. 2016. Analisis Penerapan Pajak Dengan Withholding Tax

System Tehadap Pajak Penghasilan Pasal 4 Ayat 2 pada PT. Bank SulutGo di Kota

Manado. Universitas Sam Ratulangi. EMBA, ISSN 23031174 